\title{
Teaching Language and Teaching Literature in Virtual Environment by Maria Luisa Carrio-Pastor (eds)., Springer Verlag, Singapore, 2019. XXI+293 pp. ISBN 978-981- 13-1358-5 (eBook)
}

\author{
Amare Tesfie Birhan \\ Bahir Dar Institute of Technology
}

Correspondence concerning this article should be addressed to Amare Tesfie Birhan, Department of English Language and Literature, Bahir Dar Institute of Technology, P.O.Box 26. Bahir Dar, Ethiopia. E-mail: amaretesfie@gmail.com

The teaching and learning of English as a foreign language have both experienced great shifts in approaches as a result of technological applications. Technology has widely changes the practice of education in general as well as English language teaching, in particular. It influences students' participation and engagement, the way the lesson is delivered, the modes the language is studied in and outside the classroom, and it also greatly improves the learning process and the relationship between the teacher and the students (Šafranj, 2013; Fuster \& Clavel, 2010; Chambers \& O'Sullivan, 2004). Technology has positive effects on learners' attitudes, thinking skills, autonomous learning, as well as learner confidence building. Furthermore, information technology has changed the traditional practice of language learning and teaching and provides a new type of literacy (Akyuz \& Yavuz, 2015; Chambers \& O'Sullivan, 2004). Thus, technology-assisted language learning has become a desired instructional tool in foreign and second language contexts.

The reviewed volume entitled Teaching Language and Teaching Literature in Virtual Environments was published in 2019 by Springer Nature Singapore Pte Ltd. It provides a panoramic explanation of the practice and application of technology for teaching English language and literature in a foreign language context. The main objective of this volume is to present the latest teaching experiences related to virtual environments and to identify the key determinants of virtual environments and the different tools used for this purpose (p. xii). It is organized into 15 individual chapters that are grouped into four sections. The contributors consider different second and foreign language learning theoretical frameworks such as usage based learning theory (Chapter, 3), Krashen's learning hypothesis Chapter, 6), and cognitive theory of multimedia learning (Chapter 10).

The first section of the book deals with methodology design for second language teaching/learning in virtual environments and is composed of five chapters. The first chapter of the first section starts with the work of 
Horn-Cheliz and Sarasa-Cabezuelo. The authors explicate information technologies to teach vocabulary skills. They also introduce a theoretical "parasitic model" to acquire second language vocabulary. Furthermore, they address the main difficulties in learning vocabulary and strategies to overcome the hurdles.

The second chapter of the first section is by Giglio, and it reports how to improve oral production skills in e-learning contexts. In this chapter, the role of activities and tools used to practice oral skills in the foreign language educational context are also presented. Accordingly, distance learning and online foreign language teaching are covered. The third chapter by Lech and Harris is about language learning on the Virtual Wild platform. The authors introduce language learning models such as usage-based learning and constructivist learning theory and their relationship with online learning and learner autonomy. They claim that learners acquire language skills while they participate in usage events. Furthermore, they also explain informal learning and an online approach to informal learning.

The intent of Chapter 4, authored by Scrivner, Madewell, Buckley and Perez is to explore the best practices in applying augmented and virtual reality technologies for second language acquisition. The main purpose of this chapter was to indicate the role of immersive technology in foreign language teaching and learning. The authors of this chapter consider various kinds of immersive technology such as aurasma, thinkLink:web 2.0 and Google Cardboards. They also explain how to design, implement, and evaluate these examples of virtual reality. Chapter 5, by Sama and Wu-dwells upon integrating 'Talk Abroad' into an intermediate foreign language course: building learner autonomy and engagement through video conversations with native speakers. It examines the efficacy and best practices in integrating a video-synchronous, computer-mediated communication tool 'Talk Abroad' into an intermediate foreign language course. The authors reported that by implementing this strategy, students showed increased autonomy in linguistic development and self-regulated learning strategies.

The second section is related to tools for second/foreign language teaching in virtual environments, covering Chapters 6-9. Chapter 6 starts with the study by Milojkovic, Teaching English by Skype: Theoretical and practical considerations from the perspective of Serbian English teachers. In this chapter, the author stated that digital technologies play a crucial role in foreign language teaching and learning. The chapter highlights that Skype is a potential tool for facilitating foreign language learning in a relaxing environment.

Chapter 7 brings Frame Net to the fore as a resource for teaching Spanish as a foreign language. The chapter is authored by Jodar-Sanchez, who elaborates how to teach vocabulary, grammar, and metaphors via Frame Net in foreign language contexts. Chapter 8 by Gomez explains how to use telecollaboration to develop soft skills in higher education foreign language programs, and it suggests that higher education instructors must be aware of new technology to effectively facilitate communication that helps learners become competent in the future jobs. Chapter 9 by Echevarria, addresses a comparative analysis of two online video conferencing initiatives for conversational practice with native speakers. The author describes and comparatively analyzes two online video conferencing initiatives utilized in Spanish courses.

The third section draws readers' attention to specific second language teaching in virtual environments. The first chapter begins with the work of Losey-Leon and Balderas entitled 'Cognitive Approach to Adaptive Testing Implementation in Virtual Maritime English Language Learning Environment Based on a Spaced Repetition System'. They stated that students have shown positive progress in their final test performance as a result of a space repetation system. Next, Ribeiro, Morgado, Gaspar and Regio explain teacher training for content and language integrated learning (CLIL) in higher education through blended learning. The chapter discusses the challenges of planning, preparing, and implementing a blended learning course in teacher training, as well as the results. The next chapter by Penalver looks into Project-Based Learning in a VirtualCclassroom: The case of English for tourism communication. Here, the author states that problem-based learning and technologymediated instruction is an effective way to enhance students' motivation and foster their thinking skills to progressively move towards the understanding of specific problems.

The fourth section looks into ideas for teaching in virtual environments. In this section, three main issues are discussed. The first is Digital Storytelling in Teacher Training: Development of basic competences, creativity and multimodal literacy by Ibarra-Rius and Ballester-Roca. The second issue is Teaching Poetry through Songs in a Virtual Environment: From students' reluctance to their quiescence by Marias, Penalver and Lopa. The last issue is Reflexion Analysis and Language Practice: From individual critical thinking to collaborative learning using 
blogs in a literature class, which is authored by Giralt and Murray. These researchers explore how technology can be a valuable resource for storytelling in teacher education, for teaching poetry, and for individual and critical thinking and collaborative learning.

In general, this volume raises various issues concerning teaching language and literature through technology. In addition, the book introduces different technologies that can be used in foreign language teaching classrooms. The authors consider practical examples, pictures, and details, giving the reader an opportunity to choose appropriate technologies that can be applied in their contexts. The procedures to use the technology and the designs considered by the researchers are very clear. These help the language and literature teachers to fill their skill gaps regarding the use technology in language and literature classrooms. The pictures, graphs, and images in the volume also make the book very interactive and practical for language classrooms.

Hence, the volume urges language teachers to consider technology for their classrooms to enhance students' engagement and to improve language skills. It can be a good resource for foreign language teachers, educators, and researchers who are interested in considering technology for teaching language and literature. In addition, it can also be a valuable resource for scholars with an interest in technology, language, and literature teaching. Finally, although there are other volumes that are helpful for learning to use technology for language teaching and learning, this informative and user-friendly volume is still important.

Despite its importance and positive aspects, the volume lacks intensive arguments and explanations in some chapters. In addition, I observed that some contributors did not clearly show the theoretical framework that was used to design their research. Despite these shortcomings, this worthwhile and practical volume has achieved its purpose and can make practical contributions to teaching language and literature via technology.

\section{References}

Akyuz, S., \& Yavuz, F. (2015). Digital learning in EFL classrooms. Procedia-Social and Behavioral Sciences, 197, 766-769. https://doi.org/10.1016/j.sbspro.2015.07.176

Chambers, A., \& O'Sullivan, I. (2004). Corpus consultation and advanced learners' writing skills in French. ReCall, 16(1), 158-172. https://doi.org/10.1017/S095834400400121

Fuster, M., \& Clavel, B. (2010). Corpus linguistics and its applications in higher education. Revista Alicantina de Estudios Ingleses 23, 51-67.

Šafranj, J. (2013). Using information technology in English language learning procedure: blended learning. Procedia-Social and Behavioral Sciences, 83, 514-521. https://doi.org/10.1016/j.sbspro.2013.06.099 